\title{
Sapien XT Implantation in Mitral Position
}

\section{Stefano Salizzoni ${ }^{1}$, Giovanni Marchetto ${ }^{1}$, Matteo Marro ${ }^{* 1}$, Andrea Baronetto ${ }^{1}$, Marcella Jorfida ${ }^{2}$, Maurizio D Amico ${ }^{2}$, and Mauro Rinaldi ${ }^{1}$}

${ }^{1}$ Department of Surgical Sciences, Division of Cardiac Surgery, Italy

${ }^{2}$ Department of Medical Sciences, Division of Cardiology, Italy

Received: February 02, 2018; Published: February 09, 2018

*Corresponding author: Matteo Marro, Corso Bramante 88, 10126 Torino, Italy, Tel: +39-011-6335511; Email: matteo.marro1@gmail.com

\begin{abstract}
Degeneration of bioprosthesis may occur in elderly and frail patients with an extremely high risk for redo cardiac surgery. Transcatheter valve-in-valve procedures represent a valuable treatment option in high-risk patients [1,2]. However incidental findings may contraindicate the transcatheter procedure. We describe the original case of a patient who was scheduled for transapical mitral valve-in-valve, but due to a left a trial mass underwent mini-invasive surgery with successful direct mitral valve-in-valve delivery and excision of the mass.
\end{abstract}

Keywords: TAVI; Transcatheter; Mitral; Valve-in-valve; Bioprosthesis failure; Minimally invasive surgery

\section{Introduction}

Degeneration of bioprosthesis may occur in elderly and frail patients with an extremely high risk for redo cardiac surgery. Transcatheter valve-in-valve procedures represent a valuable treatment option in high-risk patient population [1-3].Usually before transcatheter valve procedures; patients are studied with CT-scan and/or transesophageal echocardiography in order to estimate the exact anatomical sizes.

\section{Case report}

An 82-years old man with rheumatic heart disease in 2007 underwent mitral valve replacement with a 27-mm Carpentier
Perimount bioprosthesis (Edwards Lifesciences, Irvine, CA, USA) via sternotomy. In January 2015 the patient was admitted for syncope with dizziness and vomiting and worsening of shortness of breath; CT head scan, ear-nose-throat evaluation and Holter ECG were normal. Transthoracic Echocardiography (TTE) showed a $43 \%$ left ventricle ejection fraction with severe mitral stenosis (mean gradient $14.5 \mathrm{mmHg}$ ) and moderate regurgitation, mild tricuspid regurgitation with $69 \mathrm{mmHg}$ of Systolic Pulmonary Artery Pressure (Figure 1). Because of age and frailty of the patient, and the history of previously implanted bioprosthesis, a trans-apical mitral valvein-valve procedure was indicated.

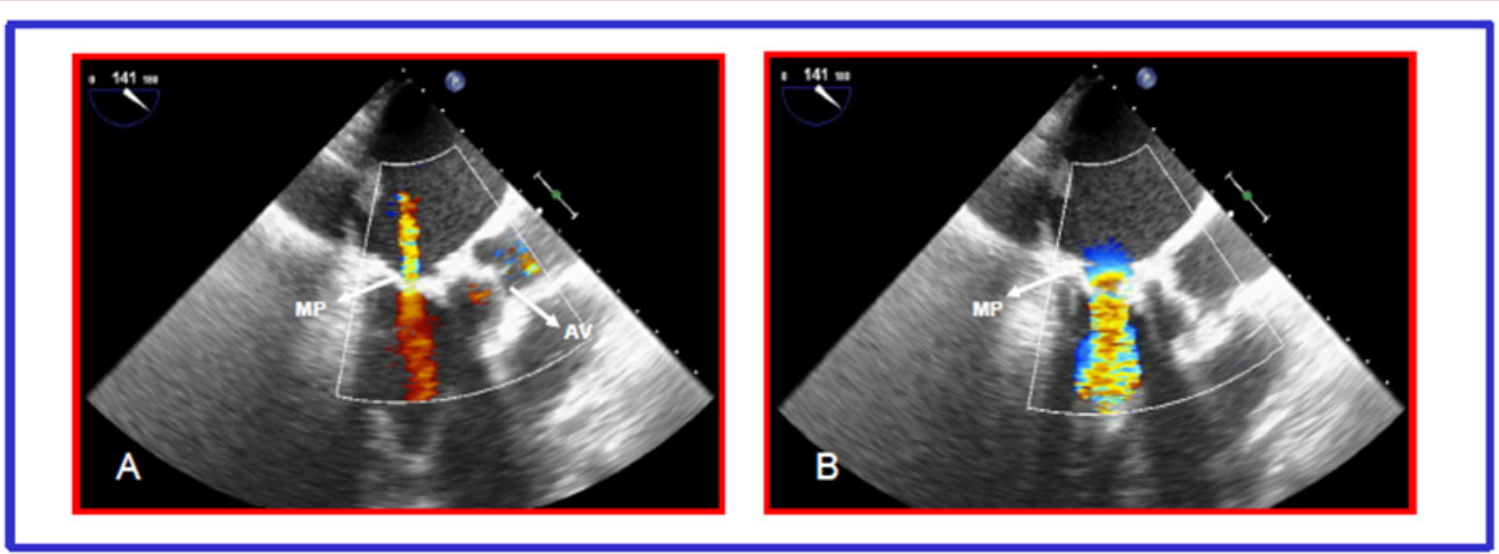

Figure 1: A)Transthoracic echocardiography showing mitral prosthesis (MP) regurgitation during systole B)Transthoracic echocardiography showing turbulent flow due to mitral prosthesis (MP) stenosis during diastole. 
Since we knew the precise size of mitral prosthesis, we did not perform any usual imaging (CT-scan or TEE) to estimate the valvular size. Unexpectedly intra-operative transesophageal echocardiography revealed the presence of a sessile and compact formation of $2.5 \times 1 \mathrm{~cm}$, situated between the roof of the left atrium and the a trial septum (Figure 2) that was not detectable on transthoracic echocardiography. Because of the risk of embolization the procedure was switched to open heart surgery through a right anterolateral mini-thoracotomy at the fourth intercostals space [4]. Cardio pulmonary by-pass through the right femoral artery, the right femoral vein and right jugular vein was established.
Under ventricular fibrillation the left a trial mass was quickly removed and a 29-mm Sapien XT (Edwards Lifesciences, Irvine, CA, USA), mounted on the transapical delivery system, was easily implanted under direct vision inside 27-mm Carpentier Perimount bioprosthesis. Intraoperative transesophageal echocardiography showed normal transvalvular gradients and a laminar flow (Figure 3). The histologic exam of the mass confirmed the hypothesis of mixoma. The patient was discharged on 6th post-operative day. The one year echo cardiographic follow-up is comparable to the one at discharge.

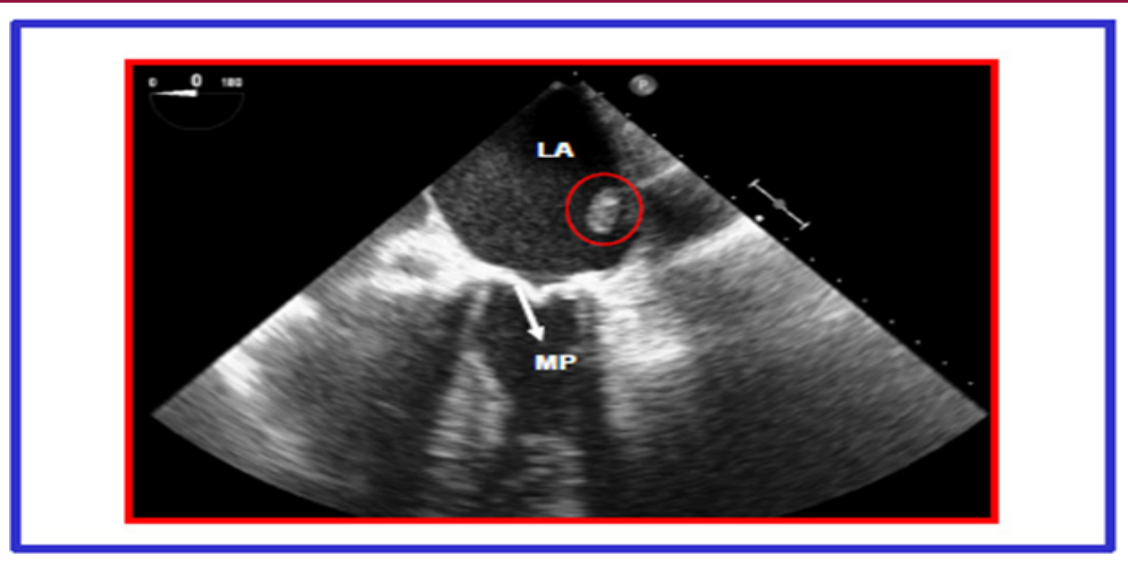

Figure 2: Transesophageal intra operative echocardiography showing left atrial (LA) mass (circled by the red line) and the mitral prosthesis (MP).

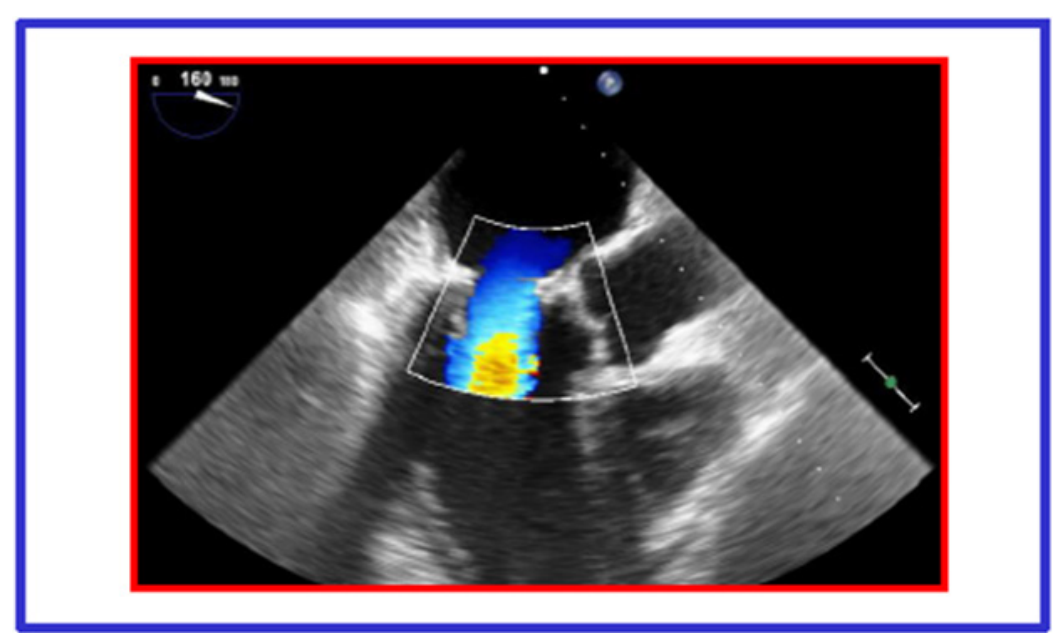

Figure 3: Post procedure transesophageal echocardiography showing regular position of mitral Prosthesis and laminar flow during systole. Left atrial mass disappeared.

\section{Conclusion}

Valve-in-valve implantation in mitral position is becoming an increasingly accepted treatment option for patients deemed unsuitable for redo operation [5-8].

This case demonstrates:

a. the importance of pre-operative imaging assessment (CT thoracic scan and/or transesophageal echocardiography) prior of any structural transcatheter intervention, even if exact anatomical sizes are known; it is not unusual to find other unexpected anatomical surprises;

b. the easiness of direct mitral valve-in-valve procedure, that to date has been described only once; 5

c. the efficacy of the procedure after one year

\section{References}

1. Cheung A, Webb JG, Wong DR, Masson JB, Carere RG, et al. (2009) Transapical transcatheter mitral valve-in-valve implantation in a human. Ann Thorac Surg 87: 18-20. 
2. A Cheung, JG Webb, M Barbanti, Freeman M, Binder RK, et al. (2013) 5-year experience with transcatheter transapical mitral valve-in-valve implantation for bioprosthetic valve dysfunction. J Am Coll Cardiol 61: 1759-1766.

3. Mc Elhinney DB, Cabalka AK, Aboulhosn JA, Eicken A, Boudjemline Y, et al. (2016) VIVID Registry. Transcatheter Tricuspid Valve-in-Valve Implantation for the Treatment of Dysfunctional Surgical Bioprosthetic Valves An International Multicenter Registry Study. Circulation 133(16): 1583-1593.

4. Marchetto G, D Armini AM, Rinaldi M, Vigano M (2005) Portaclamp in video-assisted minimally invasive cardiac surgery: surgical technique and preliminary clinical experience. Eur J Cardiothorac Surg 27: 11221124.

5. Mick SL, Roselli EE, Kapadia S, Tuzcu EM, Krishnaswamy A, et al. (2016) Postoperative Migration of an Edwards-SAPIEN XT Mitral Valve-in-Valve
Treated With Direct Vision Implantation During Beating-Heart Bypass. Ann Thorac Surg 101: 1182-1185.

6. M. Seiffert, L Conradi, S. Baldus, Schirmer J, Knap M, et al. (2012) Transcatheter mitral valve-in-valve implantation in patients with degenerated bioprostheses. JACC Cardiovasc Interv 5: 341-334.

7. AG Cerillo, F Chiaramonti, M Murzi, Bevilacqua S, Cerone E, et al. (2011) Transcatheter valve in valve implantation for failed mitral and tricuspid bioprosthesis. Catheter Cardiovasc Interv 78: 987-999.

8. Salizzoni S, Barbero C, Grosso Marra W, Moretti C, Rinaldi M, et al. (2014) Transapical implantation of an Edwards SAPIEN XT in a degenerated mitral bioprosthesis without fluoroscopic landmarks. J Card Surg 29: 625-627.

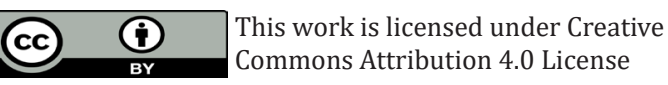

Submission Link: http://biomedres.us/submit-manuscript.php

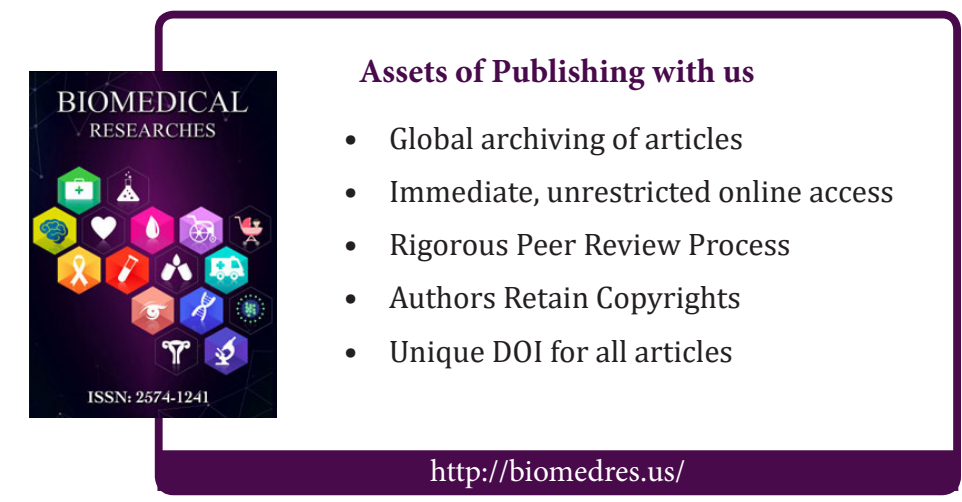

